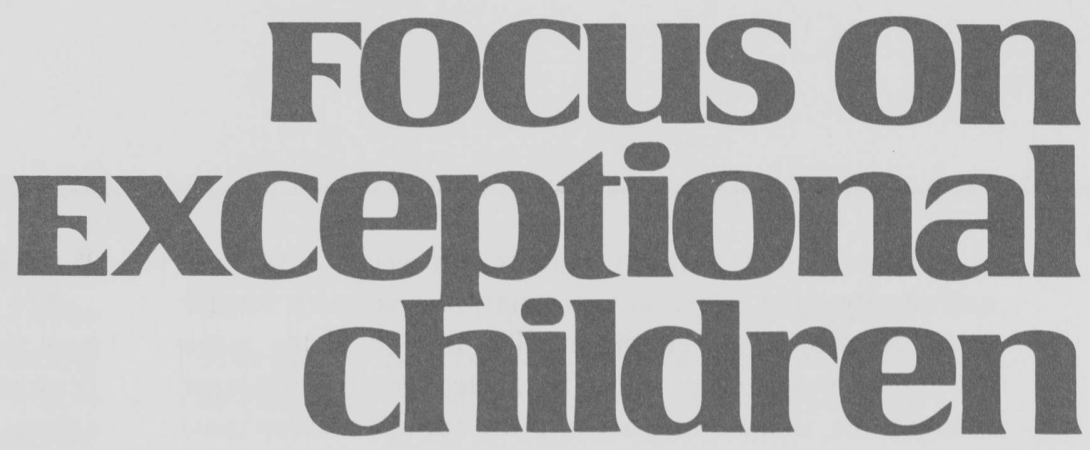

\title{
Computer Assisted Instruction: An Educational Tool
}

\section{Norma Harrod and Marilyn Ruggles}

An electronic revolution is going on in every hamlet and city in the USA. Humanity is being wired together while overhead more and more communications satellites are orbiting the globe. All of education is caught up in this revolution - as is every other facet of society. The parable of the blind men and the elephant draws immediate attention to the complexity and magnitude of the situation.

According to an old story, six blind men tried to decide what an elephant was like. The first man, feeling the elephant's flat, vertical side, concluded that the animal was similar to a wall. The second man touched a round, smooth, sharp tusk and decided that the elephant was similar to a spear. Grasping the squirming trunk, the third blind man said the elephant resembled a snake. The fourth man, who touched a knee, observed that the animal resembled a tree. From an exploration of the ear of the elephant, the fifth blind man was convinced that the animal had the shape of a fan, while an examination of the tail convinced the sixth blind man that the elephant was similar to a rope.

Each man, of course, was partially correct. But none of them was completely right, for each man had formed a picture of the entire elephant after observing only one part of it. Since each observation was incomplete, each description was incorrect because it didn't take into account all the characteristics of the elephant.

Listening to some people describe a computer is much like listening to the blind men describe the elephant. They tend to generalize from their own experiences. A person who uses a computer to help balance accounts might see it as a giant adding machine. Someone who has seen a computer play chess might think of it as a giant brain and attribute intelligence to it. A person who has watched electrical circuits being assembled and tested under computer control might see the computer as a machine for making other machines. And a person who has programmed a computer might see it as a mindless clod that can do only what it is told to do.

Mrs. Harrod and Mrs. Ruggles are affiliated with USD \#997, Lawrence Public Schools, Lawrence, Kansas. Mrs. Harrod is consultant for instructional television and related needs, and Mrs. Ruggles is a resource teacher for the gifted. Marilyn Ruggles is author of a new book. An Apple for the Teacher, published by Love Publishing Company. 
Each person is partially correct, yet none of them is completely right. Describing a computer is much harder than describing an elephant. Not only is there more ground to cover (even though an elephant is very large indeed) but, in addition, a computer (unlike an elephant) can appear in many different forms and may be used in many different ways. To further complicate the situation, the number of forms a computer can take and the number of ways it can be used are constantly growing as more and more people become familiar with computers and find new ways of using them.

The picture of a computer and what it can and cannot do will not remain fixed. It will change and adapt, as new and different uses of the computer in the world are discovered.

Much like Alice as she walked through the looking glass into a strange new world where objects were often unfamiliar, educators search in vain for the familiar blackboard and overhead projectors of the yesteryear. Instead, computers, video disks, cathode ray displays, hand-held devices that speak several languages, and television sets the size of the wall confront and confuse them. The immediate question at hand is: "What does it all mean?"

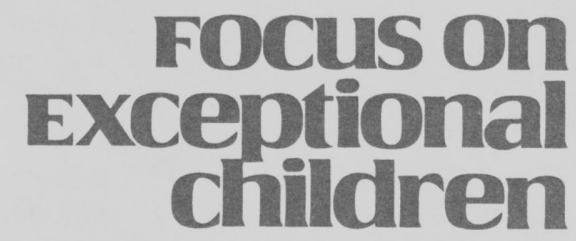

FOCUS ON EXCEPTIONAL CHILDREN (ISSN 0015-511X) (USPS 203-360) is published monthly except June, July, and August as a service to teachers, special educators, curriculum specialists, administrators, and those concerned with the special education of exceptional children. This journal is abstracted and indexed in Exceptional Child Education Resources, and is also available in microform from Xerox University Microfilms, Ann Arbor, Michigan. Subscription rates, $\$ 18.00$ per year. Copyright (๑) 1983, Love Publishing Company. All rights reserved. Reproduction in whole or part without written permission is prohibited. Printed in the United States of America. Second class postage is paid at Denver, Colorado. POSTMASTER: Send address changes to:

$$
\begin{aligned}
& \text { Love Publishing Company } \\
& \text { Executive and Editorial Office } \\
& 1777 \text { South Bellaire Street } \\
& \text { Denver, Colorado } 80222 \\
& \text { Telephone (303) 757-2579 }
\end{aligned}
$$

\section{EDITORIAL BOARD}

\author{
Edward L. Meyen \\ University of Kansas
}

Glenn A. Vergason Georgia State University

Richard J. Whelan

University of Kansas Medical Center

\section{WHAT DOES IT MEAN?}

Not since the invention of movable type have educators had so much-in terms of tools for learning-at their disposal. Educators must understand their role as change agents and be ever conscious of the responsibility to help usher in a new education age, now hovering just around the corner.

The teacher is the input the machine must have in order to produce a useful message. Faculties are the software of the new age of learning. Although education may take different forms, teachers will still be in demand. Although a machine the size of a shoebox will probably someday contain 10 times the amount of information in the Library of Congress, students will still need mentors.

Microcomputers are no panacea, nor are they a substitute for quality educational practices. Yet, if educators do not act, a new class of illiterates will be graduating from our schools-computer illiterates!

Teachers need not fear or reject the tools at hand. They must take control of them. Just as blackboards stand lifeless in the dark, so will the new teaching machines be useless without gifted, sensitive human leadership.

Reflect again upon Alice's trip through the looking glass. As she entered Wonderland, she encountered the Cheshire cat. It appeared above her in varying stages. Finally, when it was whole, Alice questioned, "Which way should I go?" The Cheshire cat replied, "Where do you want to go?" Alice retorted, "I really don't have any idea!" The Cheshire cat smiled its broad Cheshire smile and replied, "Then it doesn't make any difference which way you go, does it?"

If the educational system is to move in the right direction, educators must take the lead. Change is here, and teachers are the lead change agents.

The media have stereotyped and subtly portrayed computers as the antithesis of what it means to be human. Computers are pictured as cold steel structures driven by high technology electronics capable of performing incredible feats with lightning speed. They emote no emotion, nor do they tire. Computer experts are fond of quipping, "They never make mistakes." What could be less human?

Today's world is a high technology civilization in the midst of an information revolution. To live a rich life in such a world, a person must feel comfortable with sophisticated electronic devices and vast amounts of information. Computers will not go out of style in 10 years. If children are not taught to adapt to the rapid changes, the next 40 years will make them maladjusted to their world from the start.

\section{COMPUTER LITERACY}

Computer literacy is a progression from comfort with 
technology through skills and knowledge acquisition to ultimately using the computer as a personal tool. The attraction of computers for adults and children is a feeling of control that comes with programming or simply operating a powerful tool that serves one's own purposes.

Many believe one has to be an electrical engineer or at least mathematically inclined to program a computer. Others think one must know how a computer works in order to use it. All an individual really needs to know to communicate with a computer is a "common language." Knowing how a computer works in order to communicate with it is no more necessary than knowing how the human brain works in order to interact with a good friend!

Public media have contributed immensely to the prevailing computer image. Computers are the topic of conversation at parties, the inspiration for toys and games, and the brunt of popular jokes and cartoons. Frequently, cartoons are used to remind one that a computer, after all, is only a machine however much it takes on a personality of its own.

Computers are sometimes baffling, sometimes frightening. And nestled deep within most consciousness today is a sense of even more threatening changes. Fear stimulates a fight or flight response, and some still cry, "Let's go back to the basics!"

A critical juncture in the use of computer technology in schools is rapidly approaching. For the first time a segment of students has been weaned on computers. These youngsters play Pac-Man and Frogger as a previous generation played jacks and baseball. Their lives are touched daily with a technology absolutely unknown 30 years ago. The opportunity to use it in schools is now.

The scenario of a computer, and what it can and can't do, will not remain the same. It will change and adapt as discoveries and new uses continue to surface. The transition from an era in which the computer was an esoteric tool to one in which the computer will be an everyday necessity is imminent. Computers are becoming ubiquitous. They are used for a wide variety of tasks in a vast variety of settings. There is scarcely an area of human activity where computers are not proving useful.

Applying a computer system to the curriculum indicates a need for knowledge of the subject matter at hand. The subject patterns should be considered as a way the subject and system could be evaluated. Areas to be considered are:

1. Off-line materials that reinforce knowledge gained at the machines.

2. How the curriculum is to be managed.

3. The remedial and extended branches of the programs that provide learning experiences for all children in the classroom.

These factors must be taken into consideration before one can effectively use a computer in a classroom setting.

\section{DEFINITIONS OF COMPUTER ASSISTED INSTRUCTION}

Computer assisted instruction probably has as many different definitions as computer literacy. As time whirls forward via the high tech winds, many new definitions undoubtedly will be fed, nurtured, and ultimately digested. Computer assisted instruction, as is true with most computerese cultural components, is not very old. In reality, the meaning of computer assisted instruction is simply what the name implies:

\section{Instruction that is assisted or aided through use of the computer.}

Merely defining the term in such a fashion is, however, extremely simplistic. Much more is involved within the framework of CAI.

\section{HISTORY OF CAI}

Briefly scanning the history of CAI seems appropriate. In the early 1960s the computer's potential as an aid to learning was experimented with, researched, studied, and finally set aside for some future reference. By the early 1970s, the learning potential inherent within the computer faded into the background as interest in CAI as an instructional tool waned into remission. As is true with many things, educators seem to have to use jargon to make things sound more intellectually sound. So, no doubt, the present abbreviation CAl came into being. When educators and computerese freaks talked about or mentioned computer assisted instruction, they merely slipped out the abbreviation CAI.

The advent of computer assisted instruction brought with it the danger of temporary regression, encouraging the tendency to see learning as the acquisition and rapid recall of trivia, largely devoid of process. Even though highly interactive and often inherently interesting, computer instruction should not be thought of as the be-all, cure-all, end-all in any given content area, any more than textbooks, films, or televisions programs are. Computer assisted learning was developed to enhance educational life. It is intended to make education more comfortable, precise, and fun!

Students who have traveled a pioneer trail or have made key decisions in selling a product via computer simulation need to extend learning into the real world by 
using newspapers, maps, magazines, books, and other available materials. Computer activities should open up endless opportunities for extended learning, not serve as a microcosm that limits education to an electronic display.

Computers are at the core of the new information age. With the diverse application of computers already in place and the "Third Wave" rolling in, schools must prepare students for a computer-thrilled-and-filled future.

With the new and exciting revolutionary scene, CAI has been catapulted back into the habitation of a rich and active life. The microcomputer is the "name of the game" and one of the most important players on the computer game board is CAI.

\section{TELEVISION: 30 YEARS OF PROGRESS?}

At first, the personal computer, or microcomputer, was looked upon as an entertainment medium. As a matter of historical reference, the fledgling steps of the micro were similar to those taken by television some 30 years ago. Through the years, television has advanced very little from the original entertainment format. Although many believe television should be a strong educational tool, this philosophy has never really advanced to any significant point. Perhaps only in the realm of news coverage can the television medium at this time be considered truly educational. To an extent, television does act as an educational tool, but there is no way of truly measuring its educational worth.

Combining the mesmerizing qualities of television with the interactive capacity of the computer to create a host of imaginative friends, the computer has tapped into the child's fantasy life. Some parents see the child's attraction to the computer as a threat to development of good, sound learning habits, without recognizing the learning process children undergo in mastering the machine. Others, in contrast, view the computer software, even electronic games, as helping children develop skills that will prove important in tomorrow's electronic world.

Television did not replace the teacher. Those who predicted that this would transpire have been proven wrong. Computers certainly supplement instruction and bring a different kind of experience into the classroom, which may be useful if the programs used are good. But those who suspect that computers can replace teachers will be proved wrong. And those who look to computers to work an instant revolution in schools are probably looking at the world through rose-colored glasses.

These two extremes in thinking are without justification. Nevertheless, the effect of television on children prior to entering school has already turned them into electronic and visual learners with a vast amount of knowledge. Still, they are supposed to be no more than auditory learners.

\section{MICROCOMPUTER FLEDGLING STEPS}

The microcomputer, too, began as an entertainment medium. The first steps of the "little chipper's" life were spent on Pac Man and other amusing, if not noisy, video arcade games. But it soon became evident that the personal computer was destined to make its own significant mark in the educational arena. Whether teachers were ready to live effectively and efficiently with the new teaching tool is another part of the tale that is unfolding in school buildings all over the nation. Many teachers and administrators compare the computer with the teaching machine of the 1950s and, thus, dismiss it as a "toy," unusable in classroom situations.

Merely providing classes in programming and using a computer system in a classroom setting are not enough for today's students. Youngsters need to understand how the machines affect their lives both now and in the future. Many are horrified by electronic learning, but it $i s$ here to stay.

Reflect on the arcade setting, in which graphics change with ingenious variety, and the sounds are awesome. Video arcade games are computer-age reincarnations of pinball and pool. The educational value of most of the currently popular games is tenuous, and video games should not be put into the curriculum simply because they are a seductive teaching medium. They are not teaching independent thinking or problem solving. They may build hand-eye coordination through manipulation of objects, but they do not stretch the mind. The machine is a robot teacher, teaching robot skills with mindless repetition. The power of computer instruction, then, is that it serves the user's mind.

Control and access are the key issues when an elementary school acquires its first computer. Typically, most students use computers for tutorial and drill-andpractice programs. These programs, no matter how individually paced, put the computer in control of the child, setting up the machine as a fount of knowledge and judgment. The grade school children who do learn to control the computer - those who have the opportunity to acquire programming skills-are all too often only those identified as "gifted" or "academically talented." Most children assume a passive role, in which the machine seems to magically manipulate the learning process.

Although it was predicted by some visionaries, the explosion of micros into the home, business, and school scenes took practically everyone else by surprise. Accompanied by an array of conflicting claims and exhortations, advertisements began urging the public to catch the crest 


\section{New computer resources to teach basic skills}

\section{MICROCOMPUTERS AND TEACHERS}

Ruth Hoffman, University of Denver

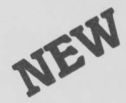

This new, versatile book covers basic information that teachers need to work with microcomputers. The author has taught this course for over a decade and brings a wealth of experience and innovative ideas to this resource. The book includes introductory concepts of computers, beginning basic programming, and the role of computers in the classroom. Super for teacher courses dealing with computer usage. This book is appropriate for inservice training for teachers and educators as well as preservice teacher training courses.

8341/paper

$8342 /$ set of 10 copies

single copy $\$ 9.95$ $\$ 89.95$

INTRODUCTION TO PASCAL

Vaughn Aandahl, George Washington High School, Denver

Ruth Hoffman, University of Denver

This new work is intended for secondary school and beginning college students and others who want to learn the PASCAL computer language. It provides an introduction to standard PASCAL programming. The approach differs from most books in that it incorporates a large number of complete programs and their documentation, sample runs, and illustrations of sample programs. This encourages students to write substantive programs. Forty-four fully documented programs are included.

8343/paper

$8344 /$ set of 10 copies

single copy $\$ 7.95$ $\$ 69.95$

\section{KIDS CAN TOUCH COMPUTERS}

A Guide to the Apple II Plus for Children

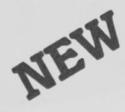

Patricia M. Shillingburg, Summit, New Jersey

This new resource was created for young children in the elementary grades. It explains simple commands, elementary programming techniques, parts of the computer, and other basic information for elementary-aged children. It includes examples and ideas that allow children to explore their own creative uses of the computer.

Graphics are introduced, with a rocket ship as the first example. Color and line drawings are discussed. This new reference work is ideal for young children in school or home.
ADULTS CAN TOUCH COMPUTERS

A Beginner's Guide to Apple Computers

Patricia M. Shillingburg, Summit, New Jersey

This book is intended for anyone who is starting to use an Apple computer for the first time. It starts at the very beginning and takes you step-by-step through the basic information you need. It discusses the basic parts of the computer and gives useful hints on programming, graphics, and introductory commands. No prior computer experience is necessary to enjoy this hands-on book.

You will be able to draw pictures, write programs, and understand your computer better... one step at a time. Try it and see for yourself how useful this beginner's guide can really be!

8349/paper $8350 /$ set of 10 copies single copy $\$ 7.95$ $\$ 69.95$

\section{AN APPLE FOR THE TEACHER}

Marilyn Ruggles, Lawrence Public Schools, Kansas

This new resource is intended for people who are new to the microcomputer, and particularly the Apple II. It starts with the basic parts of the computer, then covers the microcomputer, the monitor, and the disk drive, plus keyboard and operational information.

The book is actually a tutor in itself. It moves you from one level to another with ease. Activities are included, which make your acquaintance with the Apple II a joy. It talks about programming and tutors you in writing your first program. The section on graphics lets you make pictures on the monitor screen with dots of light.

The author suggests that educators should first identify instructional needs, locate appropriate software, and then buy the hardware. A discussion on software evaluation is included. You'll be confident after you use this book. It is self-paced and perfect for individuals, inservice training, or courses.

8345/paper

$8346 /$ set of 10 copies

single copy $\$ 9.95$ $\$ 89.95$

\section{MICROCOMPUTERS IN THE CLASSROOM} Alan Maddison, Thames Polytechnic, England

Microcomputers are rapidly becoming an important feature of education in all subjects and at every level. This book meets the need for a sound, practical introduction to the uses and applications of microcomputers for teaching across the curriculum and for administration.

Beginning with a concise explanation of the language and essential concepts of computer systems and software, the book then looks at introduction of the microcomputer to the classroom. The book goes on to discuss the microcomputer in school and college administration, and its ability to organize information such as pupil rolls and timetables. Perfect as a resource or for courses.

8327/paper $\$ 9.95$

\section{ORDER COMPUTER BOOKS AND SOFTWARE FROM}

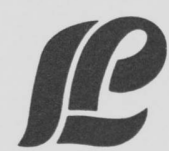
Love Publishing Company 1777 South Bellaire Street Denver, Colorado 80222 


\section{Teacher Training Software}

\section{Special Education Interactive Tutorials}

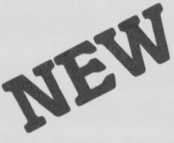

Each screen represents a set of 25 tutorials on a disk. This is a user-friendly program with good screen explanation and interaction plus visual or printed reports.

by Edward L. Meyen, University of Kansas

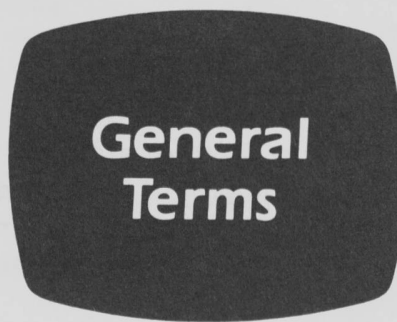

\section{Tutorial Set}

Exceptional Children Handicapped Children Disability Mildly Handicapped Multihandicapped Secondary Handicaps Health Impairments

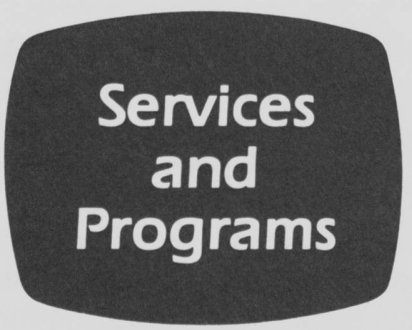

Tutorial Set
Delivery Model
Mainstreaming
Continuum of Educational
Services
Least Restrictive
Environment
Categorical
Incidence
Prevalence
Interdisciplinary

High-Risk Children

Etiology

Trauma

Organic

Syndrome

Congenital

Perinatal

Prenatal

Sensory

Bilingual

Labeling

Adaptive Behavior

Genotype

Phenotype

Prematurity

Exogenous

Endogenous

Generic

(relates to handicaps)

Referral

Screening

Child Find

Cascade Model

Special Class

Resource Teacher

Itinerant Teacher

Sheltered Workshop

Homebound Instruction

Consulting Teacher

Resource Center

Special Day School

Adaptive Physical

Education

Paraprofessional

Related Services

Average Daily

Attendance

Excess Costs

\section{Legislative Legal}

Tutorial Set

Mandate

Litigation

Advocacy

Architectural Barriers

Class Action

Equal Protection

Public Law 93-380

Public Law 94-142

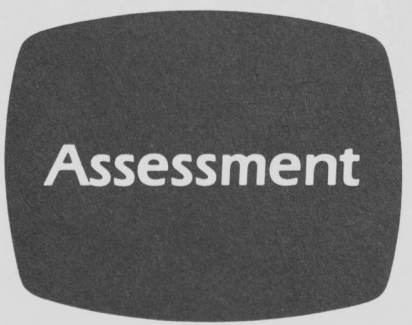

Tutorial Set

Standardized Tests

Norm-Referenced Tests

Criterion-Referenced Tests

Domain-Referenced Tests

Achievement Tests

Diagnostic Tests

Mastery Tests

Aptitude Tests

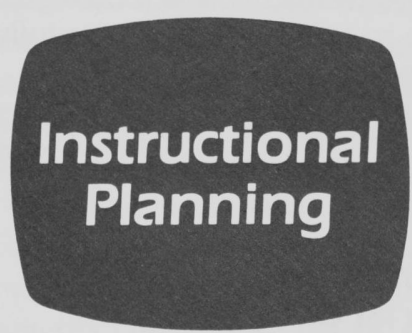

\section{Tutorial Set}

Instructional Objectives

Cognitive Objectives

Psychomotor Objectives

Affective Objectives

Terminal Criterion

Taxonomy

Remediation
Public Law 93-516

Buckley Amendment

Functional Exclusion

Expunction of Records

First Priority Children

Free and Appropriate Education

Due Process

Individualized Education

Program (IEP)

Surrogate Parent

Limited Guardianship

Dispute Settlement

Due Process Hearing

Parental Consent

Procedural Noncompliance

Monitoring

Native Language

Written Prior Notice

Anecdotal Record

Nondiscriminatory

Assessment

Formal Assessment

Informal Assessment

Mean

Standard Deviation

Reliability

Validity

Equivalent Forms

Basal Score

Ceiling

Grade Equivalent

Age Score

Percentile Rank Score

Raw Score

Mental Age

Profile

Intervention

Enrichment

Competency-Based

Instruction

Scope and Sequence

Curriculum Mapping

Individualized Instruction

Ability Grouping

Learning Strategies

Motor Skills

Comprehension Skills

Computation Skills

Task Analysis

Concept Analysis

Error Analysis

Advance Organizer

Learning Aptitude

Peer Tutoring

Basal Reading Series

Runs on Apple II computer with 48K DOS 3.3 User Manual and Trainer Manual included. 
Teacher Training Software

\section{Special Education} Interactive Tutorials

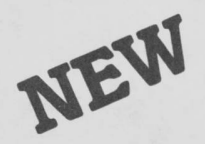

Each screen represents a set of 25 tutorials on a disk. It covers in five easy steps the information needed to work with mainstreamed children. No computer experience needed.

by Edward L. Meyen, University of Kansas

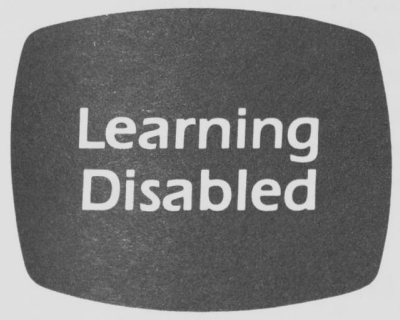

\section{Tutorial Set}

Minimal Brain Dysfunction

Perceptual Disorders

Hyperactivity

Encoding

Decoding

Figure-Ground Perception

Visualization

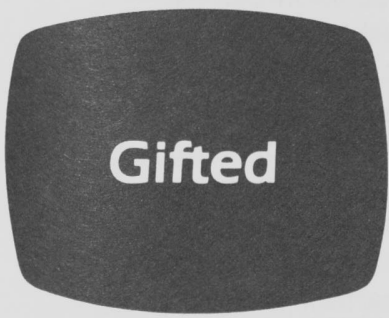

\section{Tutorial Set \\ Giftedness \\ Talent \\ Creativity \\ Precocious \\ Fluency \\ Elaboration \\ Culturally Diverse Gifted \\ Task Commitment}

Dyslexia

Dysgraphia

Dyslogia

Dyscalculia

Directionality

Mixed Dominance

Laterality

Kinesthetic Method

Agnosia

Word Recognition

Conservation

Assimilation

Abstract Reasoning

Auditory Discrimination

Distractibility

Visual Closure

Emotional Lability

Impulsivity

Mental Ability

Differential Education

Pacing

Telescoping

Pull-Out Program

Mentorship

Acceleration

Vertical Programming

Horizontal Programming

Divergent Production

Deductive Learning

Inductive Learning

Magnet School

Flexible Scheduling

Continuous Progress

Curriculum

Cluster Grouping

Discovery Learning

Mentally Retarded

\section{Tutorial Set}

Mental Retardation (AAMD)

Mild Mental Retardation

Moderate Mental Retardation

Severe Mental Retardation

Adaptive Behavior (AAMD)

Developmental Period (AAMD)

Mental Deficiency

Intelligence Quotient (IQ)

Educable Mentally Retarded

Trainable Mentally Retarded

Slow Learner

Developmental Disabilities

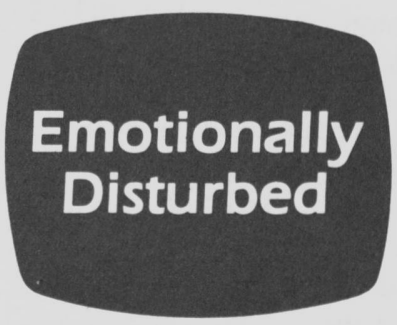

\section{Tutorial Set}

Behavior Disorder

Adjustment Reaction

Conduct Disorder

Psychosis

Neurosis

Schizophrenia

Socially Maladjusted

School Phobia

Juvenile Delinquency

Psychopathology

Psychotropic Drugs

Psychogenic
Normalization

Deinstitutionalization

Cultural Familial

Retardation

Cultural Deprivation

Sensory Deprivation

Nonverbal Ability

Perseveration

Dependence

Illiteracy

Anoxia

Epilepsy

Down's Syndrome

Feeblemindedness
Biogenic

Behaviorism

Psychoanalytic Theory

Ecologic Theory

Behavior Excesses

Behavior Deficits

Precipitating Factors

Predisposing Factors

Autism

Disinhibition

Psychosomatic

Self-Stimulatory Behavior Anorexia 


\section{Teacher Training Software}

\section{Special Education Interactive Tutorials}

Each screen represents a set of 25 tutorials on a disk. System is interactive with progress report at end of each tutorial set. Easy to use.

by Edward L. Meyen, University of Kansas

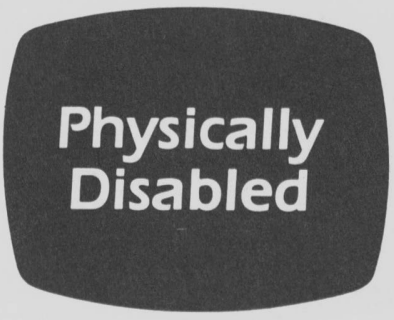

\section{Tutorial Set}

Health Impairments

Functional Disabilities

Paralysis

Paraplegia

Quadriplegia

Hemiplegia

Triplegia

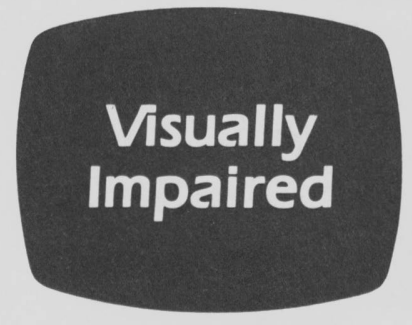

\section{Tutorial Set \\ Visual Acuity \\ Visual Impairment \\ Legally Blind \\ Low Vision \\ Vision Field \\ Visual Perception \\ Visual Reception}

Prosthetics
Orthotics
Proximal
Distal
Flexor Muscle
Extensor Muscle
Atrophy
Clonus
Metabolism
Hypotonicity
Hypoactivity
Kinesthesis
Digital Grasp
Cerebral Dominance
Cerebellum
Athetosis
Ataxia
Spasticity

Kurzweil Machine

Optacon

Perkins Brailler

Mobility Training

Orientation

Ophthalmologist

Optometrist

Optician

Cornea

Retina

Iris

Refractive Error

Strabismus

Astigmatism

Hyperopia

Myopia

Glaucoma

Educationally Blind

\section{Hearing Impaired}

Tutorial Set

Aural

Deaf

Hard of Hearing

Congenital Deafness

Adventitious Deafness

Sensorineural Hearing Loss

Audiologist

Audiometer

Audiogram

Decibel

Frequency

Air Conduction Test

Bone Conduction Test

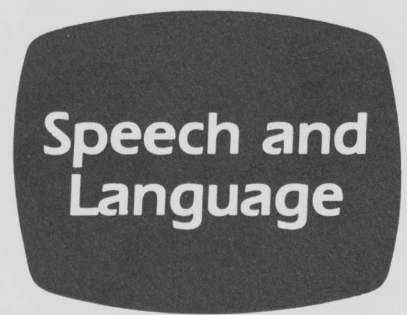

Tutorial Set

Oral Language

Intonation

Resonance

Phonation

Echolalia

Semantics

Syntax

Phoneme

Morpheme

Articulator

Palate

Larnyx
Manual Method

Oral Method

Total Communication

(For the Deaf)

Auditory Training

Auditory-Receptive Language

Auditory Integration

Auditory Discrimination

Threshold of Hearing

Ossicles

Tympanic Membrane

Tinnitis

Otitis Media
Communication Disorder Functional Speech Disorder Articulation Disorder

Substitution

Distortion

Omission

Pitch Disorder

Voice Disorder

Aphasia

Dysfluency

Dysarthria

Malocclusion

Delayed Language

Runs on Apple II computer with 48K DOS 3.3. User Manual and Trainer Manual included. 
of the "Third Wave," cover stories and TV specials have hailed the miracles of the new technologies, parent groups are holding bake sales, taking evening courses, and sending kids off to computer camps-all part of the exhaustive effort to jump on the over-obvious bandwagon.

On the other side of the coin are the "back to basics" educators and lay people who see no need for the technology, or even decry it as a manufacturer-perpetrated scam. They also call forth the idea that education's historical relationship with technology has been disastrous.

Most teachers, however, are beyond asking whether they should use the computer in instruction. The question now is, "How do I use it and what kind of computer set-up and curriculum designs are best for my class or school?"

\section{LIVING WITH CAI}

In learning to live with the computer and ccmputer assisted instruction, teachers must begin to understand what CAI includes and if or how CAI can be used to help students learn more effectively and efficiently. Serious thought must be given to the programs now in the marketplace and whether their use really enhances and improves instruction. Most lessons are written for specific purposes with a target population in mind. Hence, the learner must have the skills and strategies to effectively use the program.

Breaking down CAI into its various components is necessary to begin to discern the worth and merit of the materials involved. For purposes of this article, the following areas will be considered to be included under the umbrella of computer assisted instruction.

\section{Drill and Practice}

Drill and practice is designed to reinforce regular classroom instruction. It offers a means by which concepts presented and developed in the classroom setting may be practiced and refined using the computer. The computer can provide practice over and over again. The machine does not grow weary. Further, boys and girls seem to like to work with a computer, which may make it advantageous to use as an additional reinforcement package.

A modern theory implies strongly that certain kinds of basic skills must be not only learned but "automatized." If this learning is to happen, elementary teachers need to be taught the principle involved and learn how to deal with it.

Many computer programs are criticized for representing mere drill and practice. Too often people look at the computer and comment, "Isn't it a shame to use such a powerful intellectual tool of the 20th Century for drill and practice when it could be expanding the creative potential of students!" Certainly the computer should be used in other modes. It can be applied successfully in many different areas. It is a versatile machine. Nevertheless, if drill and practice is needed and the computer can help incorporate the activity into the elementary school curriculum, more power to the machine.

A further consideration, however, relates to the glut of drill-and-practice programs on the market. Sifting through all these in order to adequately evaluate them is difficult and time consuming. Yet, an informed evaluation is essential before incorporating them into classroom instruction.

\section{Tutorial}

Tutorial really means to stand alone as an instructional entity. Tutorials are not intended to supplement classroom teaching. The tutorial philosophy requires that the program teach rules and concepts, then evaluate the students' comprehension of the concepts and allow practice in the specific skills being taught.

\section{Instructional Game}

Instructional games, or "gaming," are situational programs in which a student has to know certain facts, be able to perform certain skills, and demonstrate mastery of specific concepts. Winning is dependent upon the mastery of specific cognitive skills.

\section{Simulation}

In simulations, certain elements of physical or social reality are abstracted. Students must interact with and, hence, become an integral part of the simulation. These programs should be used when basic concepts and principles are being learned. They must be meaningful problems. Simulations can teach specific materials, but their real educational power comes from their capacity to teach about inquiry or problem solving.

Using the computer as a tool for inquiry and not as a medium for teaching keeps the focus on the human interaction among students and between students and teacher, which is where it belongs. The computer is clearly a tool as the slide rule and calculator have been in the recent past.

\section{Problem Solving}

Problem solving involves combining already learned rules into a new, yet higher rule that will, in turn, solve the problem. 


\section{Demonstration}

Demonstration generates a visual presentation to help explain a given concept. For example, demonstrations may be given on how to operate certain types of equipment.

\section{Mini-programming for $\mathrm{CAI}$}

Mini-programs are short examples and tutorials for teachers who wish to develop their own CAI programs following one of the formats already listed. One popular mode of mini-programming is making crossword puzzles or word searches.

\section{ISSUES SURROUNDING CAI TODAY}

\section{Existing Courseware}

Most programs in the marketplace today are highly dependent on use of the verbal. Possibly, too much word usage is involved in making the programs, rendering the computer no more than an electronic ditto machine. People usually remember pictures and words most readily, and children are no exception. An example of this phenomenon is visualizing a person's face to help remember his or her name. The use of visualization as a teaching tool with great learning powers has been ignored to date in most programming. Too often, programs that present information include graphics simply tagged on as a decoration, with no real intent toward learning.

\section{Documentation}

Documentation, and how it is presented, is often verbose and cumbersome, involving more time to make the program work than the program was worth to begin with. Or a program may have no documentation at all.

Generally, the better designed the software, the less is the need for much documentation. The exceptions are mostly the fairly elaborate programs, such as a text processor or a file management program. What little documentation most good programs need can often be supplied right on the disk in the form of a short set of instructions optionally selected by the user and "help pages" judiciously placed here or there in the program.

Probably the only reason for any documentation at all with well designed programs is to make the novice computer user more comfortable. Users who are new to computers like to have some form of print material for security. If this is done, the written material must be absolutely clear and to the point. The most important function that written materials can serve is to provide easy access to information when and if the information is needed.

\section{Purchasing Power}

The school is in a peculiar position in the matter of purchasing software. Educators usually have limited monies for software purchases. Once a program is purchased, the risk that a disk may be damaged when put into the student or teacher's hands is always present.

\section{Compatibility}

Compatibility is another big bug that has plagued us. This condition should begin to stabilize soon. Within three to five years no more than 12 manufacturers of micros may remain. Fewer machine configurations would make the work of software choice and development less chaotic.

\section{Teaching Competencies}

No consensus has been reached regarding competencies teachers need for successful classroom computer implementation. The literature does suggest several key areas in which teachers should be trained, although how much training is required cannot be pinpointed at this time.

\section{Student Performance}

The effectiveness of CAI in student performance remains unanswered. It may well be as effective as traditional instruction. Some research leads one to believe that supplementary instruction with CAI leads to improved student achievement.

There is a crying need for more worthwhile research in dealing with CAI. Many questions remain unanswered. Will it, in fact, replace traditional instruction, or is it no more than another learning tool in a long line of others already available?

CAI may have the capabilities to modify the curriculum. This is one of those unanswered questions. But no educator should assume that CAI is the cure-all for the ills and pains that inflict education today. There is an outside chance it could be making these aches and pains worse.

\section{Lack of Standards}

Another vexing problem in dealing with $\mathrm{CAl}$ is that no real standard has been established to help the ordinary user define what an effective program really is. In dealing with other forms of media materials, it is fairly simple to check several reliable sources to discern the validity of 
materials. Fortunately, with microcomputer materials this is changing for the better.

But selecting and evaluating courseware is becoming more difficult because the variety of choices is ever increasing. The range of quality and appropriate application is also on the rise. A consideration in selecting courseware is whether it can be adapted for local applications. When considering the acquisition of a drilland-practice program, can material be added or deleted to match local requirements? The potential to adapt courseware is intricately bound to the issuer of software protection. If the publisher permits copying and adapting, the utility of the courseware increases tremendously. In the future, courses will be more cross-vendor microcomputer compatible. Obviously, courseware with this capability is more valuable than that usable on only one type of microcomputer when the educational institution uses several types.

Educators must work with publishers in trying to instill a sense of standards. That is difficult to do right now because schools are desperate to get things to run on machines that were purchased with the notion that a lot of good stuff is lying around. Out of desperation, schools often use very poor material.

Unfortunately, when choosing software, one does not get guarantees-at least not yet. Hopefully, the future will be brighter as more and more publishers recognize the need for easy-to-use software.

\section{EVALUATION}

The following questions should be addressed in evaluating courseware. Are the directions simple and easy to understand? First-time users do not need to know all the shortcuts and possibilities a program allows. A question-and-answer format contributes to simplicity. Are the instructions presented through the computer in an interactive mode? Let's face it-people read directions when all else fails! When instructions are required, they should be on the disk, either in the form of directions or as an optional tutorial program that teaches the user how to use the "real" program. The Bank Street Writer, a program published by Scholastic and Broderbund, is an example that enables this. This program can be used without reading the printed manual.

A tutorial should be interactive. If it is nothing more than an automated page-turner, it is worse than a printed manual. It should be short and to the point. Printed instructions do have their place. They are more useful than disks for looking up forgotten information. Nevertheless, the manual should not be the primary method for teaching someone how to use a piece of software.
First-time users of software often are frustrated because they cannot remember all that was presented in the instructions. The importance of a continuously displayed instruction window grows with the complexity of the program. In complex programs, a continuously displayed menu often makes the difference between effectiveness and ineffectiveness. Veteran users, as well as new users, sometimes input incorrect responses. A good program should provide help following an incorrect response.

Voice-synthesized instructions are an important factor if a program is likely to be used with non-readers. A beginning vocabulary could help smooth out the interface between user and computer and make or break the effectiveness of the program.

Different kinds of software require consideration of varying factors in evaluation. Evaluating a program that is a tool-such as word processing, authoring language, data base program, or graphing program-is different from evaluating a simulation or tutorial program. A tool helps do some things more effectively, efficiently, and easily without it.

\section{MICRO-PROS AND CONS}

The micro is constantly available and all-patient. It can even diagnose, thus helping students with their own instructional deficiencies. Remember, however, it is only a machine, and like any machine, it must have human input.

The computer, along with CAI, may change the complexion of the classroom and the school setting as we see it today. More individualized instruction cannot help but be made available to the student. Software will act as a supplement to the regular curriculum, as a basic course to teach a complete unit, or as a "tutor teacher" using drill and practice. The possibilities are limited only by one's own imagination.

The thesis that using the microcomputer makes children less competitive merits consideration. Following this rationale, the children are so busy concentrating their efforts on understanding the machine and on controlling the program that they haven't the time or the energy to worry about competing. But at the same time problem solving becomes more important, and the signs of monotony on the part of both student and teacher are significantly reduced.

One thing does appear quite obvious concerning the teacher in particular. The machine and its programs can be a great labor saving device for the classroom teacher. It can take over responsibilities that the teacher traditionally has had to handle, responsibilities that are at best tedious, repetitious, and time-consuming. As a result of the time and labor saving capabilities inherent in $\mathrm{CAI}$, the teacher 
has more time to give to the students, to work with them individually, to help them remedy problems.

Too, the teacher is free to work with small groups rather than having to worry about dealing with the whole class at a time. In this kind of learning environment, one hour a day with the computer can provide students with more interaction and more personal attention than can the regular classroom. One of the most unique features of the micro and of CAI is two-way instruction.

The need for better and more active learning environments for children is ever increasing. Inherent in this environment is individualized instruction. The traditional teacher-lecture syndrome will become archaic in time, if it is not already the case. The computer is by nature a nonthreatening teacher and is only as smart as the courseware it uses. But far too much of the courseware available at this printing is not too smart!

$C A I$ will never replace even a bad teacher. It can merely support secondary educational objectives. It can merely teach things. Worrying about CAI's dehumanization of people is needless. Micros are no more dehumanizing than any other medium used in education today, including the all-revered book, which certainly is an impersonal medium.

In considering $\mathrm{CAI}$, one must recognize that education is now dealing with children who are used to living in a high-tech world. They are becoming more adept with computers and are introduced at an early age to all the wonders of the computer world. Fun and games and computers are part of their lives. The mesmeric processes of television and the interactive capabilities of the computer have blended through the child's senses to make his or her own private fantasy world come alive. Education, too, must come alive if it is to survive!

High-tech children demand quality models from which to learn. The learning experiences offered through computers must be ones that cannot be accomplished by other means. These programs must successfully meet the students' concerns and needs.

\section{THE FUTURE OF CAI}

What about the future of CAI? The laser-tracked video disk has enormous software capabilities and could be the CAI of the future. In fact, the future is already here, and the marketplace is beginning to carry some of these software packages. One simple disk can provide language interactive learning in French equal to 10 years of high school and college teaching. The video disk may soon make the micro-CAI connection obsolete. Its interactive powers are awesome, and the learning capabilities are immersed with the visual.
Think also about the use of voice synthesizers. They, too, are really not futuristic but already a reality. In teaching a foreign language, a voice component instantly demonstrates pronunciation of all terms correctly and repeated at the learner's beck and call.

To spell out all the details of the technology is not possible. At what point will the average child own a portable computer more knowledgeable (and intelligent?) than any human teacher? The seeds are planted in today's technology and could bear fruit before the end of the century.

So time spins crazily by. Educators can only ponder what the computer and its assistance to instruction will be like in the fast-approaching future.

\section{BIBLIOGRAPHY}

Barnes, M. Computer literacy: An introduction. American Library Association Journal. Chicago: Spring 1983.

Bowman, R.J. A Pac-Man theory of motivation: Tactical implications for classroom instruction. Educational Technology, Sept. 1982.

Bruwelheide, J.H. Teacher competencies for microcomputer use in the classroom. Educational Technology, Oct. 1982.

Cohen, V.B. Criteria for the evaluation of microcomputer software. Educational Technology, Sept. 1982.

Corbett, M.K. Microcomputers in the classroom. Lawrence: University of Kansas Department of Curriculum and Instruction, 1982.

Evans, C. The micromillenium. New York: Washington Square Press, 1981 .

Frederick, F.J. Computers and education. School Product News, March 1983.

Grossnickle, D.R., \& Laird, B.A. Profile of change in education: Micros gain momentum. Educational Technology, Feb. 1983.

Hade, D.D. Literacy for an information society. Educational Technology, Sept. 1982.

Harcourt Brace Jovanovich. Electronic media. New York: Author, 1974

Holmes, G. Computer assisted instruction: A discussion of some of the issues of would-be implementors. Educational Technology, Sept. 1982.

Johnson, C. Problem solving. Media and Methods, May 1983.

Kaufman, R., \& Slakeur, R.G. It's human potential. Bloomington, IL: Phi Delta Kappa Educational Foundation, n.d.

Oduard, E.D. Beyond the keyboard. Learning, April/ May 1983.

Olds, H.F., Jr. Riding the microcoaster. Classroom Computer News, Sept./Oct. 1982.

Papert, S. Mindstorms. New York: Basic Books, 1980.

Polon, M. What is a personal computer? Computer Merchandising, Jan. 1982

Schulster, J. Several quarters a day keep the doctor away. Creative Computing, Jan. 1982.

Slesnick, T. Teacher inservice in computer education. Educational Computer, March/April 1983.

Steinberg, E.R. Reviewing the effectiveness of computer courseware Educational Technology, July 1983.

Stephens, D.L. How not to succeed in CAI without even trying. Classroom Computer News, Sept./Oct. 1982.

Willis, J., Smith, D., \& Hyndman, B. Peanut butter and jelly guide to computers, Beaverton, OR: Dilliham Press, 1978.

Wold, A.L., \& Hunter, B. The eclectic computer primer. Media and Methods, May/June 1983.

Zenderman, J. Toying with education. Classroom Computer News, Sept./Oct., 1982. 